\title{
Схватка Человека с Судьбой. Версия Л. Андреева (на материале пьесы «Жизнь Человека»)
}

\section{The Fight of Man with Fate. L. Andreev's Version (Based on the Play "The life of Man")}

\author{
Евгений Николаевич Филиппов \\ (Трнава, Словакия)
}

\section{Абстракт:}

Статья посвящена анализу мотивов бунта против законов Вселенной в пьесе «Жизнь Человека» Леонида Андреева. Выделен ряд бинарных оппозиций в философской картине мира автора. Выявлены значимые для исследуемых мотивов особенности в системе персонажей. Описаны главные действующие лица и своеобразие их коммуникации. Охарактеризованы герои-двойники, которые участвуют в раскрытии идеи бунта. Определены функции героев-двойников. Рассмотрены причины борьбы Человека с Судьбой. Проанализированы специфика главного конфликта и авторская концепция человека в мире.

\section{Ключевые слова:}

Леонид Андреев; Жизнь Человека; богоборчество; судьба; драматургия

\section{Abstract:}

The article is devoted to the analysis of motives of revolt against the laws of the Universe in the play "The Life of Man" by Leonid Andreev. A number of binary oppositions are identified in the philosophical picture of the author's world. Identified are signs significant for the investigated motives describing the main features in the character system. The main acting persons and the originality of their communication are described, too. The heroes-doppelgangers are characterized, who participate in the disclosure of the idea of rebellion. The functions of heroes-doppelgangers are defined. The reasons of fight of the Man with the Fate are considered. Analysed are the specifics of the main conflict and the author's conception of man in the world.

\section{Key words:}

Leonid Andreev; The Life of Man; fighting against God; fate; dramaturgy 
В пьесе «Жизнь Человека» (1907 г.) Леонид Андреев, воплощая свои философские и эстетические идеи, создает предельно обобщенную модель мира. Человек в этом мире совершенно одинок перед лицом Вечности, он находится в полной власти Судьбы и в «слепом неведении» совершает свой «жизненный путь». «Л. Андреев констатирует иррациональность мироустройства и трагедию человека, не способного понять и принять жизнь ${ }^{1}{ }$. Законы Вселенной противоречат этическим воззрениям Человека, он считает их несправедливыми. Все это обрекает Человека на отчужденность, а неготовность мириться с таким положением вещей провоцирует его бросить вызов Судьбе. Данная статья посвящена изучению мотивов бунта против законов Вселенной в пьесе «Жизнь Человека», через которые во многом раскрываются основополагающие элементы художественной модели мира произведения.

Тема богоборчества (или, шире, борьбы человека с законами Вселенной) занимает важное место в творчестве Леонида Андреева (С.Э. Сомов ${ }^{2}$ ). Преломление этой темы в пьесе «Жизнь Человека» не получило должного освещения в литературоведении, что, на наш взгляд, обедняет изучение философской концепции автора. Мотив богоборчества заявлен уже в прологе и назван «великой борьбой с непреложнымм» ${ }^{3}$. Раскрытие темы «великой борьбы» определяет не только характер конфликта, но и специфику онтологической поляризации главных действующих лиц (Человека и Некоего в сером).

Автор не наделяет Человека именем, индивидуальные и социальные черты являются второстепенными, он - обобщенный образ человека. Его жизнь и судьба также общие для всего человеческого рода. «Родивиись, он примет образ и имя человека и во всем станет подобен другим людям, уже живущим на земле. И их жестокая судьба станет его судьбою, и его жестокая судьба станет судьбою всех людей» ${ }^{4}$.

Человек бросает вызов Некоему в сером. Леонид Андреев, беседуя с корреспондентом газеты «Русское слово», так охарактеризовал этого героя: «„Некто в сером“ - не символ. Это реальное существо. В своей основе, конечно, мистическое, но изображающее в пьесе само себя: Рок, Судьба. Тут не символ Рока или Судьбы, а сам Рок, сама Судьба, представленные в образе „Некоего

1 ČUBRAKOVA, Z.: Otkrytije absurda $v$ dramach L. Andrejeva «Žizn' Čeloveka» $i$ «Sobačij val's». Russkaja literatura v XX veke: imena, problemy, kul'turnyj dialog. Vyp. 10. Poètika dramy v literature XX veka. Tomsk: Izdatel'stvo Tomskogo universiteta, 2009, s. 51.

2 SOMOV, S. È.: Meždu pravdoj i istinoj: Leonid Andrejev na putjach bogoborčestva. Mogilev: MGU im. A. A. Kulešova, 2011.

3 ANDREJEV, L. N.: Sobranije sočinenij. V 6-ti t. T. 2. Rasskazy; P’jesy. 1904-1907. Moskva: Chudožestvennaja literatura, 1990, s. 444 .

4 Ibidem, s. $443-444$. 
в сером“» ${ }^{5}$. По мнению Г. Д. Гачева, для того, чтобы представление «могло состояться, не только человек должен быть виден в своих пределах, но и сверхличная сила должна быть упруга, определена, конечна - иначе никакого взаимодействия не получится» ${ }^{6}$.

Пространственно Некто в сером означен, овнешнен в антропоморфном образе. Он буквально отъединяется от условного пространства серой комнаты в прологе ( «Несльино отделяется от стены прильнувший к ней Некто в сером»7). А вот однозначно вербализовать его затрудняются даже сами герои пьесы. «Отец (обращаясь к тому углу, где неподвижно стоит Он). Боже! [...]. Если ть сделаешь так, я всегда буду верить в тебя и ходить в иерковь» ${ }^{8}$. Среди реплик Жены Человека встречаются «бог», «жизнь»: «Господи боже! Будь нам милосердным и добрым Отцом» ${ }^{9}$, «Нет, Бог не допустит этого» ${ }^{10}$, «Не нужно бояться! Ты сильный, ты гениальныц̆, и ты победишь жизнь» ${ }^{11}$, «Боже, я прошу тебя, оставь жизнь моему сыну. [...] Господи, ты понимаешь, не могу» ${ }^{12}$. Человек, обращаясь к нему, называет его «бог», «дьявол», «рок», «жизнь» («A mbl, я не знаю, кто тьл - Бог, дьявол, рок или жизнь» $\left.{ }^{13}\right)$. Все эти наименования относятся к единой сущности, выраженной в образе Некоего в сером. Одной из причин подобной номинативной плотности является гносеологическая «беспомощность» языка, о которой говорит в своей работе С. А. Демидова: «Парадоксален, по мнению писателя, язык людей, имеющий антиномическую природу. Подобная парадоксальность ведет к принципиальной невыразимости бытия языковыми средствами, что делает мир до конца непознаваемым» ${ }^{14}$. Говоря о включенности понятия судьбы в образ Некоего в сером, стоит еще упомянуть аллюзию из сравнения в прологе: «Слегка подняв голову, Он начинает говорить твердым, холодным голосом, лишенным волнения и страсти, как-

5 Ibidem, s. 554 .

6 GAČEV, G. D.: Soderžatel'nost' chudožestvennych form. Ėpos. Lirika. Teatr. Moskva: Izdatel'stvo Moskovskogo universiteta; Izdatel'stvo «Flinta», 2008, s. 245.

7 ANDREJEV, L. N.: Sobranije sočinenij. V 6-ti t. T. 2. Rasskazy; P’jesy. 1904-1907. Moskva: Chudožestvennaja literatura, 1990, s. 443 .

8 Ibidem, s. 450.

9 Ibidem, s. 457.

10 Ibidem, s. 459 .

11 Ibidem, s. 461.

12 Ibidem, s. 479 .

13 Ibidem, s. 483.

14 DEMIDOVA, S. A.: Mirovozzrenije Leonida Andrejeva: istoriko-filosofskij analiz. Avtoreferat dissertacii na soiskanije učenoj stepeni kandidata filosofskich nauk. Moskva, 2008, s. 13. 
наемный чтеи, с суровым безразличием читающий Книгу Судеб» ${ }^{15}$. И образ Старух, похожих на древнегреческих Мойр, также отсылает нас к понятию судьбы, а Старухи и Некто в сером - представители одного «мира».

Таким образом, мы приходим к выводу, что Некто в сером - это не только бог, дьявол, судьба и даже не только жизнь, поскольку он посвящен и участвует в таинствах рождения и смерти Человека (стоит на границе бытия и небытия), более того, именно он держит свечу, символизирующую жизнь. Некто в сером объединяет в себе все эти понятия и становится персонифицированным образом мироустройства, Вселенной с ее законами, существующей в вечности. Во избежание путаницы уточним, что в данном исследовании указанные выше обозначения Некоего в сером мы будем использовать в качестве синонимов.

Бросая вызов Судьбе, Человек бросает вызов мироустройству. Неприятие этого мира происходит по нескольким причинам. Во-первых, социальная несправедливость. «Странно: так много хороших людей на свете, а человек может умереть с голоду. Отчего это?» ${ }^{16}$, «Там бесшумно, как призраки с горящими глазами, скользили красные и зеленые автомобили, и люди сидели в них, и смеялись, и лениво смотрели по сторонам, - а у меня этого нет!» ${ }^{17}$. «Над озером богатый ресторан сверкал огнями, как царствие небесное, и там ели! Министрь во фраках, какие-то ангель с бельми крыльями разносили бутерброды и пиво, и там ели, там пили! Я есть хочу! Маленькая женка, я есть хочу!» ${ }^{18}$ - в этом примере контрастное изображение социального неравенства доведено до гротескной формы. С одной стороны, «царствие небесное» со сниженными плотскими образами еды, с другой - простое физиологическое желание человека поесть и литота, выраженная на лексическом, стилистическом и словообразовательном уровнях через обращение «маленькая женка». В пьесе присутствуют и другие примеры социального неравенства, приводящего к искажению сознания героя («мои дворцы походят на толстые пироги с жирной начинкой, а иеекки - на гороховые колбасы» ${ }^{19}$ и т. д.).

Другая причина - это несоответствие законов Вселенной представлениям Человека о должной этике и справедливости. Главным преступлением Некоего в сером против человеческой морали является смерть ребенка и горе матери («Ты женщину обидел, негодяй! Ты мальчика убил!» ${ }^{20}$ ). «Равнодушие и жестокость

15 ANDREJEV, L. N.: Sobranije sočinenij. V 6-ti t. T. 2. Rasskazy; P’jesy. 1904-1907. Moskva: Chudožestvennaja literatura, 1990, s. 443 .

16 Ibidem, s. 459 .

17 Ibidem, s. 460 .

18 Ibidem.

19 Ibidem.

20 Ibidem, s. 483. 
рока рождаются здесь не из злой воли Некто в сером (или Высшего Разума), а из непонимания человеком этого универсального закона» ${ }^{21}$. И в-третьих, бунт против мира обусловлен гордостью Человека, нежеланием мириться с властью Судьбы. «В движениях своих Человек легок и быстр, как молодое животное, но позы он принимает свойственнье только человеку: деятельно-свободнье и гордые» ${ }^{22}$, «Человек (становится в гордую и смелую позу вызова и бросает в тот угол, где стоит Неизвестный, дубовый листок со словами)» ${ }^{23}$. После Молитвы отца, где Человек говорил, что он «гордо терпел» все удары Судьбы, следует диалог Жены и Человека:

Жена. Я боюсь, что не совсем смиренна была твоя молитва, мой друг. В ней как будто звучала гордость.

Человек. Нет, нет, жена, я хорошо говорил с ним, так, как следует говорить мужчинам. Разве покорных льстецов он должен любить больше, чем смельх и гордых людей, говорящих правду $?^{24}$

Прямого диалога (при всех обращениях, вызове на бой, молитве, проклятии и т.д.) между Человеком и Неким в сером не происходит, как и прямого (физического) акта борения. Главный конфликт смещен в сознание героя. Прямая коммуникация невозможна по причине разной природы героев. Некто в сером - объективно существующая реальность, незримо присутствующая в жизни Человека («ИЯ, тот, кого все называют Он, останусь верным спутником Человека во все дни его жизни, на всех путях его. Не видимый Человеком и близкими его, Я буду неизменно подле, когда он бодрствует и спит, когда он молится и проклинает. В часы радости, когда высоко воспарит его свободный и смельй дух, в часы уныния и тоски, когда смертным томлением омрачится душа и кровь застынет в сердце, в часы побед и поражений, в часы великой борьбы с непреложным - Я буду с ним. - Я буду с ним» $\left.{ }^{25}\right)$. А Человек, находясь в плену Судьбы, не в силах ее познать («Ограниченный зрением, он никогда не будет видеть следующей ступени, на которую уже поднимается нетвердая нога его; ограниченный знанием, он никогда не будет знать, что несет ему грядущий день, грядущий час - минута. И в слепом неведении своем, томимый предчувствиями,

21 PEČENKINA, A. O.: Tri teatra Leonida Andrejeva: ontologija avtora i jeje otraženije v modifikacijach dramatičeskogo konflikta. Avtoreferat dissertacii na soiskanije učenoj stepeni kandidata filologičeskich nauk. Moskva, 2010, s. 16.

22 ANDREJEV, L. N.: Sobranije sočinenij. V 6-ti t. T. 2. Rasskazy; P'jesy. 1904-19o7. Moskva: Chudožestvennaja literatura, 1990, s. 458.

23 Ibidem, s. 461.

24 Ibidem, s. 480.

25 Ibidem, s. 444. 
волнуемый надеждами и страхом, он покорно совершит круг железного предначертания» $\left.{ }^{26}\right)$, при этом он является еще и заложником собственного сознания, своих представлений о мироустройстве. «Экзистенциальный порыв к свободе принимает форму протеста человека против несправедливо устроенного мира, Создателя. Бунт героев Андреева - трагедия метафизического прозрения, приведшего к осознанию собственной несвободы» ${ }^{27}$.

Во второй картине Человек вызывает на бой Некоего в сером. В репликах Человека выстраивается оппозиция Человек/Бог. «Твоей зловещей косности я противопоставлю мою живую и бодрую силу; мрачности твоей - мой яркий и звонкий смех! Эй, отражай удары! У тебя каменный лоб, лишенный разума, бросаю в него раскаленные ядра моей сверкающей мысли; у тебя каменное сердие, лишенное жалости, - сторонись, я лью в него горячую отраву мятежных криков! Черною тучею твоего свирепого гнева затмится солнце, - мы мечами осветим тьму! Эй, отражай удары! [...] Побеждая, я буду петь песни, на которые откликнется вся земля; молча падая под твоим ударом, я буду думать лишь о том, чтобы снова встать и ринуться на бой! В моей броне есть слабые места, я знаю это. Но, покрытый ранами, истекающий алой кровью, я силы соберу, чтобы крикнуть: ты еще не победил, злой недруг человека! [...] Так разделаемся мы с жизнью, моя маленькая женка, не правда ли? Пусть она хмурится, как слепая сова при солнце, - мы заставим ее ульбнуться!» ${ }^{28}$.

Выделим ряд оппозиций, проявляющихся в этой реплике: «косность/живость», «мрачность/ясность», «внерациональность/рациональность», «безэмоциональность/эмоциональность», «тьма/свет». Эти бинарные оппозиции участвуют в определении онтологической сущности Человека и Некоего в сером.

Победа над Судьбой мыслится Человеком в противлении ее власти до последнего вздоха («И, умирая на поле брани, как умирают храбрые, одним лишь возгласом я уничтожу твою слепую радость: я победил! Я победил, злой враг мой, ибо до последнего дыхания не признал я твоей власти!» ${ }^{29}$, «проклятием я побеждаю тебя. [...] Вали меня наземь, вали - я буду смеяться и кричать: будь проклята! Клещами смерти зажми мне рот - последней мыслью я крикну в твои ослиные уши: будь проклята, будь проклята! [...] Я исчез, но исчез, повторяя: будь проклята,

26 Ibidem.

27 DEMIDOVA, S. A.: Mirovozzrenije Leonida Andrejeva: istoriko-filosofskij analiz. Avtoreferat dissertacii na soiskanije učenoj stepeni kandidata filosofskich nauk. Moskva, 2008, s. 14.

28 ANDREJEV, L. N.: Sobranije sočinenij. V 6-ti t. T. 2. Rasskazy; P’jesy. 1904-1907. Moskva: Chudožestvennaja literatura, 1990, s. 461-462.

29 Ibidem, s. 462. 
будь проклята!» ${ }^{30}$ ). Разум и эмоциональность (смех, крик) становятся не только атрибутивными признаками Человека, но и оружием в борьбе с Судьбой.

В последней реплике Человека обнажается его одиночество перед Богом: «Где мой оруженосец? - Где мой меч? - Где мой щит? Я обезоружен!» - Скорее ко мне! - Скорее! - Будь проклят!» ${ }^{31}$. Если во второй картине в эпизоде «вызова на бой» рядом с Человеком его «оруженосец» («Нас двое. Ть хорошая жена, ты моя верная подруга, ты храбрая маленькая женщина, и, пока мы с тобой, нам никто не страшен» ${ }^{32}$ ), то в пятой картине Человек в последней битве абсолютно один, на его призывы никто не откликается. Заметим, что этот эпизод в некотором смысле созвучен предсмертному монологу Сирано де Бержерака в одноименной пьесе Эдмона Ростана.

Некто в сером остается ко всему, что происходит в жизни Человека, равнодушным, в том числе к «вызову на бой», «молитве» и «проклятию». «В этом мире нет ни справедливости, ни гнева божьего, нет и милости. Есть только каменное лицо равнодушной судьбы, олицетворяемой фигурой Некоего в сером» ${ }^{33}$. Это определяет характер трагедии существования Человека в мире. Схватка Человека с Судьбой и его смерть остаются незамеченными, как падение Икара в картине Питера Брейгеля Старшего («Падение Икара» ок. 1558 г.). Борьба становится личной трагедией Человека, разворачивающейся в его сознании.

Maria Buzas говорит о том, что «сопротивление Человека судьбе является только квазиконфликтом. Хотя Человек вступает в борьбу с роком, но ответом на его бунт служит молчание. Нет настоящего конфликта, ведь Человек не имеет возможности выбора: не он выбирает свой путь, вся его жизнь предрешена уже до его рождения» ${ }^{34}$. Далее Maria Buzas отмечает, что «внешне жизнь Человека протекает так, как это рассказал в Прологе Некто в сером. Однако героя отличает от схемы его внутреннее сопротивление, его бунт» ${ }^{35}$, но она не признает за этим конфликта. На наш взгляд, конфликт в пьесе «Жизнь Человека» более, чем «реальный». Конфликт происходит в сознании главного героя (на «локализацию самого драматического конфликта в сознании

\footnotetext{
30 Ibidem, s. 483.

31 Ibidem, s. 500.

32 Ibidem, s. 462.

33 BUZAS, M.: Principy sceničeskogo voploščenija v p’jese Leonida Andrejeva «Žizn’ čeloveka». Budapest: Sub Rosa, 2005, s. 111.

34 Ibidem, s. 105.

35 Ibidem, s. 111.
} 
человека» ${ }^{36}$ указывает А. О. Печенкина), который бунтует, в том числе против предрешенности. Человек не выбирает «свой путь», но он наделен разумом, и это определяет возможность реализации конфликта (подробнее о специфике конфликта см. выше).

По мнению M. Buzas, «в невозможности или, точнее, в бессмысленности сопротивления року кроется космический пессимизм авторской концепции драмы» ${ }^{37}$. Исследовательница приводит в своей работе пример противоположной точки зрения А. Блока. Приведем также диалог Леонида Андреева с актером, игравшим в спектакле роль Человека, из воспоминаний В. В. Вересаева:

- Так вы играете «человека» большим, могучим, не сдающимся перед роком? Bот! Вот именно так и надо его играть! A то все обо мне говорят: «пессимист»!

-Вы- пессимист? Какой же вы, Леонид Николаевич, пессимист? Я удивля-яюсь! Hanpomuв!

- Да? Ну, вот видите! То есть, знаете, удивительно, - все меня считают пессимистом. Это полное непонимание меня. ${ }^{38}$

Как мы видим, нецелесообразно однозначно говорить о пессимизме пьесы. Возможна различная интерпретация, которая может зависеть и от особенностей сценического воплощения.

Леонид Андреев оставляет финал открытым: победил ли Человек Судьбу, не покорившись ей, или проиграл эту схватку вечно непоколебимому Некоему в сером? Иванов-Разумник называет этот поединок странным, «в котором, быть может, есть два победителя и наверное нет ни одного побежденного» ${ }^{39}$. Он говорит об объективной победе Некоего в сером и субъективной победе Человека. «И если даже согласиться, что Человек умер не победителем, то разве не ясно зато во всяком случае, что он умер не побежденным?» ${ }^{40}$

У Человека в пьесе есть герои-двойники, которые также выражают идею бунта против законов мира. Один из двойников-бунтарей - это сын Человека, о жизни которого мы узнаем только из реплик других персонажей. Из речи Человека, перебирающего детские игрушки: «А вот кивер, картонный, плохонький кивер, который со смехом я сам примерял, когда покупал его в лавке. - Ты кто? - «Я рыцарь, папа. Я самый сильный, смельй рыцарь». -Куда идешь ты,

36 PEČENKINA, A. O.: Tri teatra Leonida Andrejeva: ontologija avtora i jeje otraženije v modifikacijach dramatičeskogo konflikta. Avtoreferat dissertacii na soiskanije učenoj stepeni kandidata filologičeskich nauk. Moskva, 2010, s. 21.

37 BUZAS, M.: Principy sceničeskogo voploščenija v p'jese Leonida Andrejeva «Žizn' čeloveka». Budapest: Sub Rosa, 2005, s. 105.

38 VERESAJEV, V. V.: Sobranije sočinenij. V 5 t. T. 5. Vospominanija. Moskva: «Pravda», 1961, s. 415.

39 IVANOV-RAZUMNIK, R. V.: O smysle žizni. Sankt-Peterburg, 1910, s. 122.

40 Ibidem, s. 121. 
мой маленький рыцарь? - Дракона убивать я иду, мильй папа. Я иду освободить пленных, папа». - Иди, иди, мой маленький рыцзарь» ${ }^{41}$. Сын выступает в роли рыцаря, как и его отец. Мотив рыцарства часто звучит в пьесе. Жена говорит Человеку: «За тобой стоит твой оруженосеи, мой гордый рыцарь!» 42 . Обратим внимание, что здесь вновь звучит идея «гордости». «Плохонький» военный головной убор созвучен словам Человека, прозвучавшим чуть ранее в этой же картине опять же в контексте рыцарства: «Бедный мой оруженосец, верный хранитель моего иступившегося меча, - плох твой старый рыццарь, не держит оружия его дряхлая рука» ${ }^{43}$. Примечательна еще одна деталь: Человек примеряет кивер со смехом (ср. смех как оппозиция к безэмоциональной Вселенной, и смех как оружие в борьбе с ней). А в роли Рока выступает дракон, с которым идет бороться сын, чтобы «освободить пленных» (идея противления несвободе).

Еще один важный герой-двойник - это игрушечный паяц. «А вот и наш неизменный паяи, со своей глупой и милой рожей. Но какой он ободранный - точно из сотни битв вырвался он, но все так же смеется и так же краснонос. Ну, позвени же, друг, как ты звенел прежде. Не можешь, нет? Один только бубенчик остался, ты говоришь?» ${ }^{44}$. Как игрушечный паяц зависит от Человека, так и Человек - лишь марионетка в руках Судьбы. Паяц - тот же рыцарь, который «вырвался из сотни битв». Он «ободранный», как и Человек с его «плохонькой» амуницией. Он стар и не может «звенеть, как прежде», как и Человек, который в юности, вызывая Некоего в сером на бой, предлагал ему «позвенеть щитами» («Эй, эй, выходи на бой! Поблестим мечами, позвеним щитами» ${ }^{45}$ ). Сын целовал «смешное лицо» паяца, и Жена целует своего рыцаря-мужа. И, конечно, паяц окружен смехом: он смеется сам, и он вызывает смех у других. В пятой картине присутствуют два зеркальных эпизода с героями-двойниками. Первый - Человек бросает игрушечного паяца на пол, а, когда поднимает, паяц продолжает смеяться: «Ну, так я же брошу тебя на пол! (Бросает) [...] (Поднимает, c трудом нагибаясь) Все смеешься?» ${ }^{46}$. И второй эпизод в «Проклятии Человека»: «Вали меня наземь, вали - я буду смеяться и кричать» ${ }^{47}$. В образе игрушечного паяца концентрировано содержится философская концепция человека в мире. Помимо мотива смеха и присущих ему функций, мотива бунта против законов

41 ANDREJEV, L. N.: Sobranije sočinenij. V 6-ti t. T. 2. Rasskazy; P’jesy. 1904-19o7. Moskva: Chudožestvennaja literatura, 1990, s. 478.

42 Ibidem, s. 461.

43 Ibidem, s. 477 .

44 Ibidem, s. 478.

45 Ibidem, s. 462.

46 Ibidem, s. 478.

47 Ibidem, s. 483. 
мироздания, идеи зависимости от Судьбы (паяц такая же игрушка в руках Человека, как Человек в руках Судьбы) в этих зеркальных эпизодах проявляется еще одно принципиально важное различие между Человеком и Роком: Человек раскаивается, проявляет милосердие и поднимает паяца, а Судьба с «каменным лицом» и с «каменным сердцем, лишенным жалости», безразлична к Человеку.

Данное исследование показывает, насколько важными являются мотивы бунта против законов Вселенной в философско-эстетической концепции пьесы «Жизнь Человека» Л. Андреева. Анализ этих мотивов позволил более детально рассмотреть онтологически значимые элементы в художественной модели мира, что дало основание для выделения ряда бинарных оппозиций. Также были определены специфические функции «смеха», «крика» и выявлены некоторые особенности системы персонажей. Полученные результаты могут быть использованы при системном анализе творчества Леонида Андреева.

\section{Литература:}

ANDREJEV, L. N.: Sobranije sočinenij. V 6-ti t. T. 2. Rasskazy; P’jesy. 19o4-19o7. Moskva: Chudožestvennaja literatura, 1990. $559 \mathrm{~s}$.

BUZAS, M.: Principy sceničeskogo voploščenija v p’jese Leonida Andrejeva «Žizn’ čeloveka». Budapest: Sub Rosa, 2005, s. 101-114.

ČUBRAKOVA, Z.: Otkrytije absurda v dramach L. Andrejeva «Žizn' Čeloveka» $i$ «Sobačij val's». Russkaja literatura v XX veke: imena, problemy, kul'turnyj dialog. Vyp. 10. Poètika dramy v literature XX veka. Tomsk: Izdatel'stvo Tomskogo universiteta, 2009, s. 47-67.

DEMIDOVA, S. A.: Mirovozzrenije Leonida Andrejeva: istoriko-filosofskij analiz. Avtoreferat dissertacii na soiskanije učenoj stepeni kandidata filosofskich nauk. Moskva, 2008.

DRJAGIN, K. V.: Èkspressionizm v Rossii (dramaturgija Leonida Andrejeva). Vjatka: Izdanije Vjatskogo pedagogičeskogo in-ta, 1928. $84 \mathrm{~s}$.

GAČEV, G. D.: Soderžatel'nost' chudožestvennych form. Èpos. Lirika. Teatr. Moskva: Izdatel'stvo Moskovskogo universiteta; Izdatel'stvo «Flinta», 2008. $288 \mathrm{~s}$.

IVANOV-RAZUMNIK, R. V.: O smysle žizni. Sankt-Peterburg, 1910. $310 \mathrm{s.}$

LICHAČEV, D. S., PANČENKO, A. M.: «Smechovoj mir» Drevnej Rusi. Leningrad: «Nauka», 1976. $204 \mathrm{~s}$.

PEČENKINA, A. O.: Tri teatra Leonida Andrejeva: ontologija avtora i jeje otraženije $v$ modifikacijach dramatičeskogo konflikta. Avtoreferat dissertacii na soiskanije učenoj stepeni kandidata filologičeskich nauk. Moskva, 2010. 
SOMOV, S. È.: Meždu pravdoj i istinoj: Leonid Andrejev na putjach bogoborčestva. Mogilev: MGU im. A. A. Kulešova, 2011. 196 s.

VERESAJEV, V. V.: Sobranije sočinenij. V 5 t. T. 5. Vospominanija. Moskva: «Pravda», 1961 , s. $395-421$.

About the author

\section{Evgenii Nikolaevich Filippov}

University of Ss. Cyril and Methodius, Faculty of Arts, Department of Russian Studies, Trnava, Slovakia

filippov1@ucm.sk

https://orcid.org/0000-0003-1669-2497 
